\title{
Analytical method for lipoperoxidation relevant reactive aldehydes in human sera by high-performance liquid chromatography-fluorescence detection
}

Mahmoud H. El-Maghrabey ${ }^{\mathrm{a}, \mathrm{b}}$, Naoya Kishikawaa ${ }^{\mathrm{a}}$ Kaname Ohyama ${ }^{\mathrm{a}}$, Naotaka Kuroda ${ }^{\mathrm{a}, *}$

${ }^{a}$ Course of Pharmaceutical Sciences, Graduate School of Biomedical Sciences, Nagasaki University, 1-14 Bunkyo-machi, Nagasaki 852-8521, Japan

${ }^{\mathrm{b}}$ Analytical Chemistry Department, Faculty of Pharmacy, Mansoura University, Mansoura 35516, Egypt

Short title: HPLC-FL detection analysis of reactive aldehydes

Subject Category: Chromatographic techniques

* Corresponding author. Tel.: +81 95819 2894, fax: +81 95819 2444,

E-mail address: n-kuro@nagasaki-u.ac.jp (N. Kuroda). 


\begin{abstract}
A validated, simple and sensitive HPLC method was developed for the simultaneous determination of lipoperoxidation relevant reactive aldehydes; glyoxal (GO), acrolein (ACR), malondialdehyde (MDA) and 4-Hydroxy-2nonenal (HNE) in human serum. The studied aldehydes were reacted with 2,2'-furil to form fluorescent difurylimidazole derivatives that were separated on $\mathrm{C}_{18}$ column using gradient elution and fluorescence detection at excitation and emission wavelengths of 250 and $355 \mathrm{~nm}$, respectively. The method showed good linearity over the concentration ranges of $0.100-5.00,0.200-10.0$, 0.200-40.0 and $0.400-10.0 \mathrm{nmol} / \mathrm{mL}$ for GO, ACR, HNE and MDA, respectively, with detection limits ranged from 0.030 to $0.11 \mathrm{nmol} / \mathrm{mL}$. The $\%$ RSD of intra-day and inter-day precision didn't exceed 5.0\% and 6.2\%, respectively, and the accuracy (\%found) ranged from 95.5 to 103\%. The proposed method was applied for monitoring the four aldehydes in sera of healthy, diabetic and rheumatic human subjects with simple pretreatment steps and without interference from endogenous components. By virtue of its high sensitivity and accuracy, our method enabled detection of differences between analytes concentrations in sera of human subjects at different clinical conditions.
\end{abstract}

Keywords: Lipoperoxidation; aldehydes; HPLC-fluorescence detection; 2,2'-furil; diabetes; rheumatoid arthritis. 


\section{Introduction}

Oxidative stress has been implicated in a range of diseased conditions, including diabetes [1], hypertension [2], atherosclerosis [3], Alzheimer's disease [4] and rheumatoid arthritis [5]. Oxidants, including reactive oxygen species (ROS), are constantly produced in cells through normal metabolic processes. Oxidative stress occurs when the balance of oxidants within the cell exceeds the levels of antioxidants [6]. The hallmarks of oxidative stress include lipoperoxidation, protein oxidation and DNA oxidation. The peroxidation of membrane-derived lipid molecules is known to give rise to many products through a series of iterative oxidation and cleavage reactions. The most commonly characterized products are aldehydes. Damage caused by aldehydes can disturb the function of proteins and enzymes, initiates further damage to lipids and lead to the formation of DNA adducts. In addition, some reactive aldehydes such as glyoxal (GO), acrolein (ACR), malondialdehyde (MDA) and 4-Hydroxy-2-nonenal (HNE) can reduce intracellular glutathione levels, thereby leading to increased oxidant imbalance within the cell $[6,7]$. These types of molecular distresses may lead to cell death [8].

Among the carbonyl compounds produced as a result of lipoperoxidation, alkanals are the least reactive. Alkenals containing unsaturated bond, such as ACR, are usually an order of magnitude more reactive than the alkanals. 4Hydroxy-2-alkenals, such as HNE, are extremely reactive due to increased reactivity of the $\alpha, \beta$-unsaturated bond by the close proximity of the electronwithdrawing hydroxyl at $\mathrm{C}_{4}$ and the $\mathrm{C}_{1}$-carbonyl group [6]. The di-aldehydes, such as GO and MDA, are also very reactive since the two aldehydic moieties can form Schiff bases with amino acids [6]. In consequence, these four lipoperoxidation relevant reactive aldehydes (LPRRAs) namely; GO, ACR, MDA and HNE are considered the most reactive and harmful, and could be 
used as good biomarkers of oxidative damage and disease progression [9]. So there is a strong need for a method that could simultaneously determine LPRRAS to investigate their pattern in healthy and diseased condition.

Levels of these LPRRAs have been determined in different matrices either individually or in combination with each other or other carbonyl compounds as has been reviewed by Shibamoto [10]. Some methods were recently published for determination of GO such as GC-MS [11], GC-flame ionization detection [12] and HPLC-FL following derivatization with 5,6diamino-2,4-hydroxypyrimidine sulfate [13] or 4-methoxy-o-phenylenediamine [14]. ACR has been determined by HPLC-FL after derivatization with luminarin [15] or 3-aminophenol [16]. MDA has also been determined by LC and GC methods [17], HPLC-CL using potassium permanganate/formaldehyde system [18], capillary electrophoresis-FL after derivatization with thiobarbituric acid [19] and surface-enhanced Raman spectroscopy after derivatization with thiobarbituric acid also [20]. As for HNE, HPLC-UV detection based on derivatization with 2,4-dinitrophenylhydrazine [21] and GC-electron capture detection [22] have been reported for its determination. Only one GC method with nitrogen phosphorous detection was developed for the simultaneous determination of ACR, MDA and HNE in lipids following derivatization with n-methylhydrazine [23]. Another LC-MS method has been developed for simultaneous determination of several classes of aldehydes including ACR, MDA and HNE in exhaled breath condensate after derivatization with 2,4dinitrophenylhydrazine [24]. These methods involved the use of expensive sophisticated instrumentation that are not available in many laboratories and are applied to either lipids [23] or exhaled breath condensate only [24]. This initiates the present study to develop and validate a new analytical method for the simultaneous determination of these LPRRAs in human serum and estimation of their pattern in diseased conditions. 
In the present study, a sensitive and selective derivatizing reagent, 2,2'-furil, was used in the presence of ammonium acetate for pre-column derivatizaion of LPRRAs to convert them to highly fluorescent difurylimidazole derivatives. A reaction scheme illustrating the mechanism of fluorogenic derivatization reaction of the targeted aliphatic aldehydes with 2,2'-furil is presented in Fig. 1. 2,2'-Furil has been applied in our laboratory as a new fluorogenic derivatizing agent for the determination of medium chain-length aliphatic aldehydes in human serum [25]. This reagent has been proven to be selective for aldehydes; also it is stable and safe compared with other fluorescence derivatization reagents such as hydrazine based reagents [25]. In this study, we adopted the gradient elution to separate the peaks of LPRRAs derivatives from blank peaks within short time. Hence, the proposed method was applied for the determination of LPRRAs in sera of diabetic and rheumatoid arthritis patients with simple pre-treatment steps without interference from biological components. The patterns of these oxidative stress biomarkers in sera of healthy, diabetic and rheumatic patients were investigated.

\section{Experimental}

\subsection{Materials and reagents}

All reagents were of analytical grade and used as received. Acrolein monomer $(90 \%, w / v)$ and 2,2'-furil were obtained from Tokyo Chemical Industries (Tokyo, Japan). Glyoxal (40\%, w/v) and malondialdehyde tetrabutylammonium salt (96\%, w/w) were supplied from Sigma Aldrich (St. Louis, MO, USA). 4-Hydroxy-2-nonenal (1\%, w/v) was purchased from Cayman Chemical Company (Ann Arbor, MI, USA). Ammonium acetate, citric acid monohydrate and phosphate buffer saline (PBS) powder were purchased from Wako Pure Chemical Industries (Osaka, Japan). Methanol (HPLC grade) was obtained from Kanto Chemical Company (Tokyo, Japan). Glacial acetic acid and di-sodium hydrogen phosphate dodecahydrate were purchased from 
Nacalai Tesque (Kyoto, Japan). The water used was purified by a Simpli Lab UV (Millipore, Bedford, MA, USA). Stock solutions of GO, ACR, MDA and HNE (5.0 mM) were prepared in methanol. To obtain reproducible results, a mixed standard solution containing the four aldehydes $(200.0 \mu \mathrm{M}$ of each aldehyde) was daily prepared by diluting the stock solutions with methanol then diluted with the same solvent as needed to obtain the required concentrations. 8.0 mM 2,2'-furil and 3.0 M ammonium acetate were prepared in methanol and glacial acetic acid, respectively. 0.01 M PBS was prepared in water. All solutions were kept in the refrigerator at $4{ }^{\circ} \mathrm{C}$ except for the HNE stock solution and the mixed standard solution containing the four aldehydes were kept at $-80{ }^{\circ} \mathrm{C}$.

\subsection{Instruments}

The HPLC system consisted of two Shimadzu LC-20AD pumps (Kyoto, Japan), a Rheodyne injector (Cotati, CA, USA) with a $20 \mu \mathrm{L}$ sample loop, a Shimadzu RF-20AXS fluorescence detector and an EZ Chrom Elite chromatography data acquisition system (Scientific software, Pleasanton, CA, USA). The fluorescence spectra were recorded on a Shimadzu RF-1500 spectrofluorophotometer. Horiba F22 pH-meter was used to adjust buffer $\mathrm{pH}$. The samples were centrifuged using Himac CR 15 refrigerated centrifuge (Hitachi Koki Co., Ltd., Tokyo, Japan). Yamato HF-41 heating block (Tokyo, Japan) was used in derivatization process. The solutions were evaporated in Eyela CVE-3100 solvent centrifugal evaporator (Tokyo Rikakikai Co., Ltd., Tokyo, Japan).

\subsection{Chromatographic conditions}

Chromatographic separation was achieved on a Cosmosil $5 \mathrm{C}_{18}$-MS II column (250 mm $\times 4.6 \mathrm{~mm}$, $5 \mu \mathrm{m}$ particle size) from Nacalai Tesque INC. 
(Kyoto, Japan). Two mobile phases; A: methanol-citrate phosphate buffer $(\mathrm{pH} 5.0 ; 5.0 \mathrm{mM})(48: 52, \mathrm{v} / \mathrm{v})$ and B: methanol-citrate phosphate buffer $(\mathrm{pH}$ $5.0 ; 5.0 \mathrm{mM})(80: 20, \mathrm{v} / \mathrm{v})$ were pumped at a flow rate of $1.0 \mathrm{~mL} / \mathrm{min}$ in the following gradient elution mode: $100 \% \mathrm{~A}(0-22.0 \mathrm{~min}), 0 \% \mathrm{~B}$ to $100 \% \mathrm{~B}$ linearly (22.0-32.0 min) and 100\% B (32.0-40.0 min). The fluorescence detector wavelengths were set at $355 \mathrm{~nm}$ for emission and $250 \mathrm{~nm}$ for excitation. Analysis was performed at ambient temperature.

\subsection{Assay procedure for aliphatic aldehydes in human serum}

To $50 \mu \mathrm{L}$ of human serum, spiked with the targeted aldehydes, $950 \mu \mathrm{L}$ of methanol was added to denature proteins. The mixture was mixed for 30 seconds then centrifuged at $2200 \times g$ for $5 \mathrm{~min}$ at $4^{\circ} \mathrm{C}$. A $500 \mu \mathrm{L}$ portion of the supernatant was transferred to screw-capped vial followed by $400 \mu \mathrm{L}$ of 8.0 mM 2,2'-furil and $150 \mu \mathrm{L}$ of $3.0 \mathrm{M}$ ammonium acetate. The mixture was heated at $90{ }^{\circ} \mathrm{C}$ for $30 \mathrm{~min}$ then cooled. The solution was evaporated and the residue was reconstituted with $100 \mu \mathrm{L}$ of the mobile phase then mixed for $1 \mathrm{~min}$ and filtered through $0.45 \mu \mathrm{m}$ cellulose acetate membrane filter. An aliquot of $20 \mu \mathrm{L}$ was injected into the HPLC system. A blank experiment was carried out simultaneously using unspiked serum. For preparation of reagent blank and standard mixture chromatograms, the previous procedure was adopted with replacing serum with $50 \mu \mathrm{L}$ of PBS.

\subsection{Clinical samples}

Serum samples from 6 diabetic patients ( 2 females, 4 males; mean age $53.2 \pm 10.7$ ) and 6 rheumatoid arthritis patients (3 females, 3 males; mean age $56.7 \pm 15.3$ ) in addition to a control group of 6 healthy subjects (2 females, 4

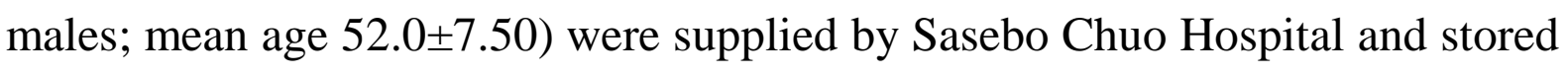
at $-80{ }^{\circ} \mathrm{C}$ until analyzed. The present experiments were approved by the Ethics 
Committee of the School of Pharmaceutical Sciences, Nagasaki University, and performed in accordance with the established guidelines.

\subsection{Statistical analysis}

The data are presented as mean \pm standard error (SE) for the number of experiments. In order to compare the levels of the four targeted aldehydes in the three studied groups (healthy subjects, diabetic, and rheumatoid arthritis patients), Kobayashi decision tree [26] was employed. Bartlett's test was used as a test for the equality of $\mathrm{k}$ variances. It was found that the $\mathrm{k}$ sampled populations have unequal variances and Steel's Dwass test for comparing all pairs was used. All the statistical tests were two-sided at a significant level of $\alpha=0.05$.

\section{Results and discussion}

\subsection{Optimization of chromatographic conditions}

Initially, isocratic separation of the four analytes was investigated but this was not possible due to the different natures of the analytes since GO, ACR and MDA are hydrophilic while, HNE is lipophilic. Hence, the gradient elution program described under "Chromatographic conditions" was adopted for separation of the analytes within a reasonable time. Different columns were tested with mobile phases comprising different organic modifiers and buffers at different $\mathrm{pH}$ values and ionic strengths. Optimum separation was accomplished on $\mathrm{C}_{18}$ column using the mobile phase containing methanol as organic modifier and $5.0 \mathrm{mM}$ citrate-phosphate buffer of $\mathrm{pH} 5.0$ as aqueous phase in the gradient elution mode described earlier.

Typical chromatograms for standard mixture of the four LPRRAs derivatives and reagent blank are shown in Fig. 2. Baseline resolution of the 
four LPRRAs derivatives was achieved with the retention times $\left(t_{R}\right)$ of 3.1, 8.0, 19.8 and 36.9 min for GO, ACR, MDA and HNE, respectively and a total chromatographic run was completed with less than 40 min. Blank peaks were observed in all chromatograms, this might be attributed to the presence of short chain aliphatic aldehydes as impurities either in solvents or reagents, or incorporated from the air during the derivatization procedure [27]. Additionally, 2,2'-furil was reported to react with ammonium acetate in the presence of glacial acetic acid, in the absence of any aldehydes, producing trifurylimidazole fluorescent product [28]. Meanwhile, when injecting ACR following derivatization, two peaks were observed at $t_{R}$ of 8.0 and $24.8 \mathrm{~min}$. This might be attributed to presence of ACR dimer as an impurity in standard solution [29] which react with 2,2'-furil giving a fluorescent derivative at $t_{R}$ of $24.8 \mathrm{~min}$. Nevertheless, this peak did not interfere with the peaks of target analytes proving selectivity of the proposed method.

\subsection{Optimization of derivatization conditions}

In order to obtain higher sensitivities, derivatization conditions including reagent concentrations, heating temperature and time were optimized using standard mixture of the four LPRRAs (5 nmol/mL each) spiked in human serum. The influence of 2,2'-furil concentration was investigated over the range of 0.4-12.0 mM, where increasing the concentration of the regent produced a corresponding increase in the peak areas of the formed derivatives with maximum response obtained using $8.0 \mathrm{mM}$ (Fig. 3A). Also, the effect of ammonium acetate concentration was studied from 0.5 to $4.0 \mathrm{M}$. Increasing the concentration of ammonium acetate resulted in proportional increase in the peak areas of ACR and MDA derivatives with minor effects on the peak areas of GO and HNE derivatives. The optimum concentration was found to be $3.0 \mathrm{M}$ ammonium acetate giving maximum and constant peak areas for all aldehydes 
derivatives (Fig. 3B). The effect of heating temperature was also investigated, where it was found that increasing the temperature gave rise to corresponding increase in the peak areas up to $90{ }^{\circ} \mathrm{C}$ after which further increase in the temperature resulted in a decrease in the analytical response (Fig. 3C) which may be attributed to instability of the reaction product at higher temperatures. Thus, $90{ }^{\circ} \mathrm{C}$ was used as the optimum heating temperature for performing the reaction. The influence of heating time on the derivatization reaction was also investigated where; maximum peak areas were obtained upon heating for 30 min after which a slight decrease of the peak areas was observed (Fig. 3D).

\subsection{Validation Study}

Validation of the proposed method was performed following U.S. Guidance for Industry on Bioanalytical Method Validation [30]. Calibration curves for the four LPRRAs were constructed in human serum under the optimum derivatization and separation conditions. A linear dependence of concentration on average peak areas was achieved with correlation coefficients ranged from 0.997 to 0.9998 . Limit of detection (LOD) were calculated as the concentration with a signal-to-noise $(\mathrm{S} / \mathrm{N})$ ratio of 3 . Calibration ranges, regression equations and LOD of the four LPRRAs are summarized in Table 1.

The proposed method was found to be about 10, 59 and 1.5 times more sensitive than the reported GC-flame ionization detection [12] and HPLC-FL methods [13,14] for GO, respectively, 2.5 times more sensitive than the reported HPLC-FL method [15] for ACR and HPLC-CL method for MDA [18] and 1.5 times more sensitive than HPLC-FL [16] for ACR. On the other hand, the proposed method showed comparable sensitivity to the reported HPLC-UV method [21] for HNE, yet this method involved time consuming and tedious extraction procedure. Even though some of the published literature for LPRRAs exhibits higher sensitivity than the present method, but they either entail the use 
of sophisticated very expensive instrumentation [11, 22-24] or instruments that are unavailable in many laboratories [20] or the use of a non-selective derivatizing agent such as thiobarbituric acid (TBA) that probably yields false high results due to likely interference from other TBA-reactive compounds including reducing sugars, pyrimidine and prostaglandin endoperoxides [19]. 2,2'-Furil was proven as a stable derivatization reagent which is relatively safe compared with hydrazine reagents and highly selective relative to TBA.

Accuracy of the proposed method was evaluated by the closeness of mean test results obtained by the proposed method to the true concentration of the analytes. Serum samples spiked with a standard mixture of aldehydes at three different concentrations were analyzed for assessment of accuracy. Percentage recoveries were expressed as [(amount found/amount spiked) x100].

To evaluate the intra- and inter-day precision of the proposed method; five replicates of three sets of human serum samples spiked with standard mixture of LPRRAs at three concentration levels were analyzed. It was found that $\%$ RSD values for intra-day $(n=5)$ and inter-day $(n=5)$ precision were $0.50-5.0 \%$ and 1.1-6.2\%, respectively. Results of accuracy and precision studies are summarized in Table 2. These results indicate that the proposed method enables precise and accurate analysis of the targeted four LPRRAs in human serum.

\subsection{Analysis of serum samples from healthy subjects and patients}

The proposed HPLC-FL method was applied to the determination of the four LPRRAs in the sera of healthy and diseased human subjects. Figure 4 shows typical chromatograms of spiked serum and serum samples from healthy control subjects, diabetic and rheumatoid arthritis patients determined by the proposed method. Although several peaks that are attributed to the biological 
components other than the reagent blank were detected in the chromatogram of serum samples, the peaks of the studied LPRRAs could be separated and detected clearly without any interference.

The level of the target LPRRAs were compared between control subjects, diabetic and rheumatoid arthritis patients using Steel's Dwass test [26] for comparing each pair and the results are abridged in Table 3. The statistical tests were two-sided at a significant level $\alpha=0.05$. The level of the LPRRAs in healthy subjects were found to be $1.04 \pm 0.060,1.26 \pm 0.28,15.1 \pm 0.52$ and $0.960 \pm 0.060$ for GO, ACR, MDA and HNE, respectively, and these values show good agreement with other previous reports [12, 31-34].

Statistical analysis revealed the presence of significantly higher concentration of GO, ACR, MDA and HNE in diabetic patients as compared to healthy controls. The increased level of MDA and HNE in diabetic patients is attributed to catalysis of lipoperoxidation by free glucose and glycosylated collagen [35]. It had been also demonstrated that oxidation of the glycation products can release dicarbonyls such as GO and short chain aldehydes such as ACR. This process of glycoxidation takes place when there is an extra amount of glucose coupled with high levels of oxidants, and this is the case in diabetes [6]. Also, GO may arise from enzymatic and non-enzymatic degradation of glucose [36].

On the other hand, the levels of ACR, MDA and HNE were found to be significantly higher in the sera of rheumatoid arthritis patients compared to the healthy controls. Meanwhile, there was no significance difference in the concentration of GO in the two groups. The elevated levels of MDA and HNE in rheumatoid arthritis patients are probably due to high level of ROS produced by activated polymorphonuclear cells and injury resulting from ischemia and reperfusion in the inflamed joints [37]. Beside oxidative stress and increased 
lipoperoxidation, the presence of ACR at a significantly higher concentration in rheumatic group might be also attributed to the oxidative deamination of polyamines [38] which were previously detected in high levels in rheumatic patients' urine samples [39].

Comparing the levels of the four LPRRAs in rheumatic and diabetic groups, HNE and MDA were found to be present in significantly higher level in rheumatic sera than diabetic sera. Since the main source of these two aldehydes is from lipoperoxidation [37, 40], we could conclude that the rates of oxidative stress and lipoperoxidation are relatively higher in rheumatic condition than hyperglycemic one. On the other hand, the concentrations of GO and ACR were found to be significantly higher in serum of diabetic group than in rheumatic one. This might be due to the increase of glycation and glycoxidation processes in diabetic patients $[6,9]$.

It is worth noting that the present work is the first study that explores and compares the patterns of the most harmful LPRRAs (GO, ACR, MDA and HNE) in these two diseased conditions. However, there are some reports that determine these compounds in different biological, environmental or lipid matrices [10-24], none of these methods simultaneously determine these LPRRAs in human serum.

\section{Conclusion}

We developed a sensitive and accurate HPLC method with fluorescence detection for the simultaneous determination of four LPRRAs including GO, ACR, MDA and HNE using 2,2'-furil as a sensitive and selective fluorogenic derivatizing agent. The proposed method monitors the levels of such aldehydes in human serum with the aim of evaluating the oxidative status in healthy subjects and in patients suffering from diabetes and rheumatoid arthritis. The 
proposed method allowed the simultaneous determination of patterns of LPRRAs in both healthy and diseased conditions. 


\section{References}

[1] R.P. Robertson, Chronic oxidative stress as a central mechanism for glucose toxicity in pancreatic islet beta cells in diabetes, J. Biol. Chem. 279 (2004) 42351-42354.

[2] R.M. Touyz, Reactive oxygen species, vascular oxidative stress, and redox signaling in hypertension: what is the clinical significance, Hypertension 44 (2004) 248-252.

[3] N.R. Madamanchi, A. Vendrov, M.S. Runge, Oxidative stress and vascular disease, Arterioscler. Thromb. Vasc. Biol. 25 (2005) 29-38.

[4] W.R. Markesbery, Oxidative stress hypothesis in Alzheimer's disease, Free. Radic. Biol. Med. 23 (1997) 134-147.

[5] Y.Ozkan, S. Yardým-Akaydýn, A. Sepici, E. Keskin, V. Sepici, B. Simsek, Oxidative status in rheumatoid arthritis, Clin. Rheumatol. 26 (2007) 64-68.

[6] E.M. Ellis, Reactive carbonyls and oxidative stress: Potential for therapeutic intervention, Pharmacol. Ther. 115 (2007) 13-24.

[7] J.S. White, K.R. Rees, The mechanism of action of 4-hydroxynonenal in cell injury, Chem. Biol. Interact. 52 (2007) 233-241.

[8] D. Li, A. Hinshelwood, R. Gardner, G. McGarvie, E.M. Ellis, Mouse aldo-keto reductase AKR7A5 protects V79 cells against 4hydroxynonenal induced apoptosis, Toxicology 226 (2006) 172-180.

[9] K. Uchida, Role of reactive aldehyde in cardiovascular diseases, Free Radic. Biol. Med. 28 (2000)1685-1696.

[10] T. Shibamoto, Analytical methods for trace levels of reactive carbonyl compounds formed in lipid peroxidation systems, J. Pharm. Biomed. Anal. 41 (2006) 12-25. 
[11] M.Y. Wu, B.G. Chen, C.D. Chang, M.H. Huang, T.G. Wu, D.M. Chang, Y.J. Lee, H.C. Wang, C.I. Lee, C.L. Chern, R.H. Liu, A novel derivatization approach for simultaneous determination of glyoxal, methylglyoxal, and 3-deoxyglucosone in plasma by gas chromatographymass spectrometry, J. Chromatogr. A 1204 (2008) 81-86.

[12] L.A. Zardari, M.Y. Khuhawar, A.J. Laghari, Capillary GC Analysis of Glyoxal and Methylglyoxal in the Serum and Urine of Diabetic Patients After Use of 2,3-Diamino-2,3-dimethylbutane as Derivatizing Reagent, Chromatographia 70 (2009) 891-897.

[13] A. Espinosa-Mansilla, I. Durán-Merás, F.C. Cañada, M.P. Márquez, High-performance liquid chromatographic determination of glyoxal and methylglyoxal in urine by prederivatization to lumazinic rings using in serial fast scan fluorimetric and diode array detectors, Anal. Biochem. 371 (2007) 82-91.

[14] A.G. Ojeda, K. Wrobel, A.R. Escobosa, M.E. Garay-Sevilla, K.Wrobel, High-performance liquid chromatography determination of glyoxal, methylglyoxal, and diacetyl in urine using 4-methoxy-ophenylenediamine as derivatizing reagent, Anal. Biochem. 449 (2013) 5258.

[15] A. Pacia, A. Rieutorda, D. Guillaumeb, F. Traoré, J. Ropenga, H.P. Husson, F. Brion, Quantitative high-performance liquid chromatographic determination of acrolein in plasma after derivatization with Luminarin 3, J. Chromatogr. B 739 (2000) 239-246.

[16] F. Bohnenstengel, M. Eichelbaum, E. Golbs, H.K. Kroemer, Highperformance liquid chromatographic determination of acrolein as a marker for cyclophosphamide bioactivation in human liver microsomes, J. Chromatogr. B 692 (1997) 163-168. 
[17] M. Giera, H. Lingeman, W.M. Niessen, Recent Advancements in the LCand GC-Based Analysis of Malondialdehyde (MDA): A Brief Overview, Chromatographia 75 (2012) 433-440.

[18] G. Zhang, Y. Tang, X. Shi, R. Gao, Y. Sun, W. Du, Q. Fu, A chemiluminescence method to detect malondialdehyde in plasma and urine, Anal. Biochem. 443 (2013) 16-21.

[19] J.C. Cooley, C.E. Lunte, Detection of malondialdehyde in vivo using microdialysis sampling with CE-fluorescence, Electrophoresis 32 (2011) 2994-2999.

[20] D. Zhang, R. Haputhanthri, S.M. Ansar, K. Vangala, H.I. De Silva, A. Sygula, S. Saebo, C.U. Pittman Jr, Ultrasensitive detection of malondialdehyde with surface-enhanced Raman spectroscopy, Anal. Bioanal. Chem. 398 (2010) 3193-3201.

[21] H. Strohmaier, H. Hinghofer-Szalkay, R.J. Schaur, Detection of 4hydroxynonenal (HNE) as a physiological component in human plasma, J. Lipid Mediat. Cell Signal. 11 (1995) 51-61.

[22] E. Santaniello, A. Repetto, L.M. Chiesa, P.A. Biondi, Synthesis and characterization of 4-hydroxy-2-nonenal derivatives for gas chromatographic analysis with electron capture detection (GC-ECD), Redox Rep. 12 (2007) 55-58.

[23] T. Miyake, T. Shibamoto, Simultaneous determination of acrolein, malonaldehyde and 4-hydroxy-2-nonenal produced from lipids oxidized with fenton's reagent, Food Chem. Toxicol. 34 (1996) 1009-1011.

[24] R. Andreoli1, P. Manini, M. Corradi, A. Mutti, W.M. Niessen, Determination of patterns of biologically relevant aldehydes in exhaled breath condensate of healthy subjects by liquid chromatography/atmospheric chemical ionization tandem mass spectrometry, Rapid Commun. Mass Spectrom. 17 (2003) 637-645. 
[25] M.F.B. Ali, N. Kishikawa, K. Ohyama, H.A. Mohamed, H.M. AbdelWadood, A.M. Mohamed, N. Kuroda. Chromatographic determination of aliphatic aldehydes in human serum after pre-column derivatization using 2,2'-furil, a novel fluorogenic reagent, J. Chromatogr. A 1300 (2013) 199- 203.

[26] K. Kobayashi, K.S. Pillai, Y. Sakuratani, T. Abe, E. Kamata, M. Hayashi, Evaluation of statistical tools used in short-term repeated dose administration toxicity studies with rodents, J. Toxicol. Sci. 33 (2008) 97-104.

[27] M. Eggink, M. Wijtmans, R. Ekkebus, H. Lingeman, I.J. de Esch, J. Kool, W.M. Niessen, H. Irth, Development of a selective ESI-MS derivatization reagent: synthesis and optimization for the analysis of aldehydes in biological mixtures, Anal. Chem. 80 (2008) 9042-9051.

[28] S. Wang, Q. Gu, X. Chen, T. Zhao, Y. Zhang, Research on the reaction of furil with ammonium acetate, Eur. J. Chem. 2 (2011) 173-177.

[29] M. Delgado, M. Desrochesa, F. Ganachaud, Ionic oligomerization of acrolein in water, RSC Adv. 3 (2013) 23057-23065.

[30] U.S. Department of Health and Human Services Food and Drug Administration, Center for Drug Evaluation and Research (CDER), and Center for Veterinary Medicine (CVM), Guidance for Industry, Bioanalytical Method Validation, http://www.fda.gov/downloads/Drugs/Guidances/ucm070107.pdf (accessed 18 Jan 2014).

[31] K. Sakata, K. Kashiwagi, S. Sharmin, S. Ueda,Y. Irie, N. Murotani, $\mathrm{K}$. Igarashi, Increase in putrescine, amine oxidase, and acrolein in plasma of renal failure patients, Biochem. Biophys. Res. Commun. 305 (2003) 143-149. 
[32] A.S. Sim, C. Salonikas, D. Naidoo, D.E. Wilcken, Improved method for plasma malondialdehyde measurement by high-performance liquid chromatography using methyl malondialdehyde as an internal standard, J. Chromatogr. B 785 (2003) 337-344.

[33] D. Del Rio, A.J. Stewart, N. Pellegrini, A review of recent studies on malondialdehyde as toxic molecule and biological marker of oxidative stress, Nutr. Metab. Cardiovasc. Dis. 15 (2005) 316-328.

[34] I. Dalle-Donne, R. Rossi, R. Colombo, D. Giustarini, A. Milzani, Biomarkers of oxidative damage in human disease, Clin. Chem. 52 (2006) 601-623.

[35] M. Hicks, L. Delbridge, D.K. Yue, T.S. Reeve, Catalysis of lipid peroxidation by glucose and glycosylated collagen, Biochem. Biophys. Res. Commun. 151 (1988) 649-655.

[36] Y. Han, E. Randell, S. Vasdev, V. Gill, V. Gadag, L.A. Newhook, M. Grant, D. Hagerty, Plasma methylglyoxal and glyoxal are elevated and related to early membrane alteration in young, complication-free patients with Type 1 diabetes, Mol. Cell Biochem. 305 (2007) 123-131.

[37] J.K. Gambhir, P. Lali, A.K. Jain, Correlation between blood antioxidant levels and lipid peroxidation in rheumatoid arthritis, Clin. Biochem. 30 (1997) 351-355.

[38] J.F. Steven, C.S. Maier, Acrolein: sources, metabolism, and biomolecular interactions relevant to human health and disease, Mol. Nutr. Food Res. 52 (2008) 7-25.

[39] Y. Furumitsu, K. Yukioka, A. Kojima, M. Yukioka, K. Shichikawa, T. Ochi, I. Matsui-Yuasa, Y. Nishizawa, H. Morii, Levels of urinary polyamines in patients with rheumatoid arthritis, J. Rheumatol. 20 (1993) 1661-1665.

[40] D.M. Niedowicz, D.L. Daleke, The role of oxidative stress in diabetic complications, Cell Biochem. Biophys. 43 (2005) 289-330. 
Table 1: Calibration ranges, regression equations, correlation coefficients and detection limits for the target aldehydes in spiked serum

\begin{tabular}{|c|c|c|c|c|}
\hline Compound & $\begin{array}{c}\text { Range, } \\
\mathrm{nmol} / \mathrm{mL}\end{array}$ & Regression equation $^{\text {a }}, n=3$ & $r^{\mathbf{b}}$ & $\begin{array}{l}\text { LOD }^{\mathrm{c}}, \mathrm{nmol} / \mathrm{mL} \\
\text { (pmol/injection) }\end{array}$ \\
\hline GO & $0.100-5.00$ & $Y=3.10 \times 10^{5}+8.40 \times 10^{5} X$ & 0.997 & $0.030(0.60)$ \\
\hline ACR & $0.200-10.0$ & $Y=11.5 \times 10^{5}+6.50 \times 10^{5} X$ & 0.999 & $0.060(1.2)$ \\
\hline MDA & $0.200-40.0$ & $Y=62.2 \times 10^{5}+10.3 \times 10^{5} \mathrm{X}$ & 0.999 & $0.050(1.0)$ \\
\hline HNE & $0.400-10.0$ & $Y=-6.20 \times 10^{5}+16.9 \times 10^{5} X$ & 0.9998 & $0.11(2.2)$ \\
\hline
\end{tabular}

${ }^{\mathrm{a}} \mathrm{Y}=$ peak area, $\mathrm{X}=$ sample concentration $(\mathrm{nmol} / \mathrm{mL})$.

b Correlation coefficient.

${ }^{c} \mathrm{~S} / \mathrm{N}=3$. 
Table 2: Accuracy and precision of the proposed method for the determination of BAL in the spiked enzymatic reaction mixtures.

\begin{tabular}{|c|c|c|c|c|c|c|c|}
\hline \multirow[b]{2}{*}{ Aldehyde } & \multirow{2}{*}{$\begin{array}{c}\text { Spiked } \\
\text { amount } \\
(\mathrm{nmol} / \mathrm{mL})\end{array}$} & \multicolumn{3}{|c|}{ Intra-day $(n=5)$} & \multicolumn{3}{|c|}{ Inter-day $(n=5)$} \\
\hline & & Found & $\begin{array}{c}\text { Accuracy } \\
(\%)\end{array}$ & $\begin{array}{l}\text { Precision } \\
\text { (\% RSD) }\end{array}$ & Found & $\begin{array}{c}\text { Accuracy } \\
(\%)\end{array}$ & $\begin{array}{l}\text { Precision } \\
\text { (\% RSD) }\end{array}$ \\
\hline \multirow[t]{3}{*}{ GO } & 0.200 & 0.191 & 95.5 & 4.60 & 0.193 & 96.5 & 4.10 \\
\hline & 2.00 & 1.91 & 95.5 & 5.00 & 1.91 & 95.5 & 5.30 \\
\hline & 5.00 & 4.91 & 98.2 & 1.70 & 4.90 & 98.0 & 4.10 \\
\hline \multirow[t]{3}{*}{ ACR } & 0.500 & 0.498 & 99.6 & 0.500 & 0.516 & 103 & 6.20 \\
\hline & 5.00 & 4.91 & 98.2 & 1.80 & 4.91 & 98.2 & 2.00 \\
\hline & 10.0 & 9.88 & 98.8 & 1.10 & 9.92 & 99.2 & 1.20 \\
\hline \multirow[t]{3}{*}{ MDA } & 0.500 & 0.481 & 96.2 & 3.90 & 0.494 & 98.8 & 2.10 \\
\hline & 15.0 & 14.8 & 98.7 & 1.70 & 14.8 & 98.7 & 1.40 \\
\hline & 30.0 & 29.8 & 99.3 & 0.900 & 29.7 & 99.0 & 1.10 \\
\hline \multirow[t]{3}{*}{ HNE } & 1.00 & 0.993 & 99.3 & 1.50 & 0.962 & 96.2 & 3.60 \\
\hline & 5.00 & 4.88 & 97.6 & 2.50 & 4.92 & 98.4 & 1.50 \\
\hline & 10.0 & 9.92 & 99.2 & 0.900 & 9.73 & 97.3 & 3.90 \\
\hline
\end{tabular}


Table 3: Statistical analysis of the results for determination of the target aldehydes in healthy, diabetic and rheumatic patients' sera.

\begin{tabular}{|c|c|c|c|c|c|}
\hline \multirow{2}{*}{$\begin{array}{c}\text { Groups } \\
(n=6)\end{array}$} & \multirow{2}{*}{ Parameters } & \multicolumn{4}{|c|}{ LPRRAs data } \\
\hline & & GO & ACR & MDA & HNE \\
\hline \multirow[t]{2}{*}{ Control } & Range (nmol/mL) & $0.900-1.26$ & $0.660-2.18$ & $13.4-16.6$ & $0.780-1.14$ \\
\hline & Mean \pm SE & $1.04 \pm 0.060$ & $1.26 \pm 0.28$ & $15.1 \pm 0.52$ & $0.960 \pm 0.060$ \\
\hline \multirow{2}{*}{$\begin{array}{l}\text { Diabetic } \\
\text { Patients }\end{array}$} & Range (nmol/mL) & $1.68-4.04$ & $4.60-9.29$ & 21.1-30.5 & $1.19-1.36$ \\
\hline & Mean \pm SE & $2.75 \pm 0.34$ & $6.35 \pm 0.71$ & $25.6 \pm 1.8$ & $1.27 \pm 0.030$ \\
\hline \multirow{2}{*}{$\begin{array}{l}\text { Rheumatic } \\
\text { Patients }\end{array}$} & Range (nmol/mL) & $0.700-2.06$ & 2.29-3.71 & 35.2-39.6 & $1.37-2.47$ \\
\hline & Mean $\pm \mathrm{SE}$ & $1.34 \pm 0.18$ & $2.92 \pm 0.20$ & $36.95 \pm 0.62$ & $1.78 \pm 0.17$ \\
\hline \multirow{7}{*}{$\begin{array}{c}\text { Statistical } \\
\text { analysis }\end{array}$} & Bartlett & $0.00400^{\mathrm{a}}$ & $0.0178^{\mathrm{a}}$ & $0.0328^{\mathrm{a}}$ & $0.00180^{\mathrm{a}}$ \\
\hline & Control vs $(p)^{b}$ & $0.0141^{\mathrm{a}}$ & $0.0141^{\mathrm{a}}$ & $0.0141^{\mathrm{a}}$ & $0.0141^{\mathrm{a}}$ \\
\hline & Diabetic & & & & \\
\hline & Control vs $(p)^{b}$ & $0.281^{\mathrm{c}}$ & $0.0141^{\mathrm{a}}$ & $0.0141^{\mathrm{a}}$ & $0.0141^{\mathrm{a}}$ \\
\hline & Rheumatic & & & & \\
\hline & Diabetic vs $(p)^{b}$ & $0.0349^{\mathrm{a}}$ & $0.0141^{\mathrm{a}}$ & $0.0141^{\mathrm{a}}$ & $0.0141^{\mathrm{a}}$ \\
\hline & Rheumatic & & & & \\
\hline
\end{tabular}

\footnotetext{
a $\mathbf{P}<0.05$.

b Steel's Dwass test.

c Non-significant.
} 


\section{Figure Captions:}

Fig.1. The reaction scheme for fluorogenic derivatization of target aldehydes with 2,2'-furil.

Fig.2. Representative chromatograms of (A) reagent blank, (B) standard mixture of the studied aldehydes (5 nmol/mL each), where: 1=GO, 2=ACR, 3=MDA, 4=HNE, * acrolein dimer.

Fig.3. Effects of (A) 2.2'-furil concentration, (B) ammonium acetate concentration, (C) reaction temperature and (D) reaction time on the relative peak area of the studied aldehydes derivatives $(5.0 \mathrm{nmol} / \mathrm{mL})$

Fig.4. Chromatograms of (A) healthy human serum, (B) human serum spiked with a standard mixture of the studied aldehydes $(5.0 \mathrm{nmol} / \mathrm{mL}$ each), (C) diabetic patient serum, and (D) rheumatoid arthritis patient serum; where peaks 1-4, * as in Fig.2. 
<smiles>[R]C=[O+][C-]C(=O)O[Na]</smiles>

Aldehyde

Ammonium Acetate

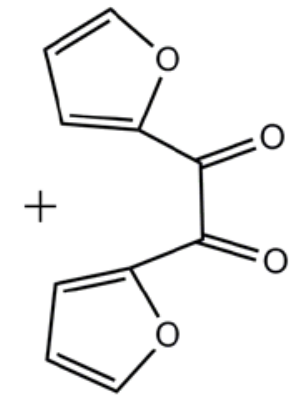

2,2' Furil

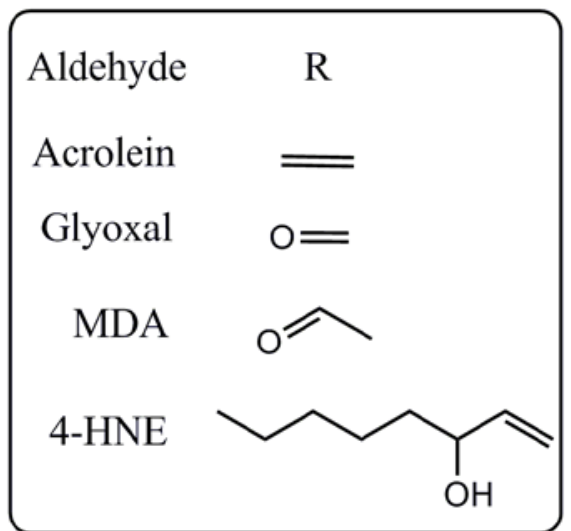

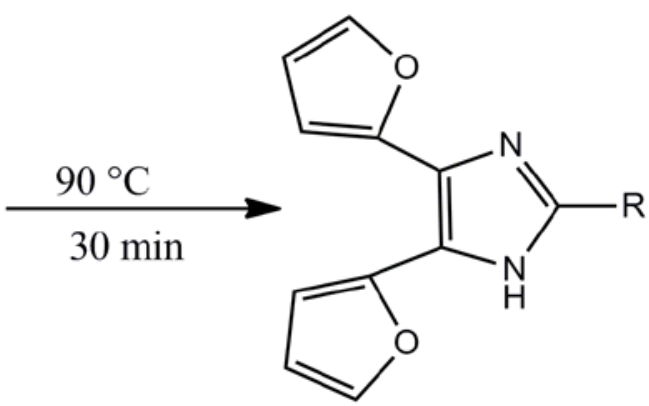

Difuryl imidazole derivative Fluoresce at $355 \mathrm{~nm}$ after excitation at $250 \mathrm{~nm}$

Figure 1 

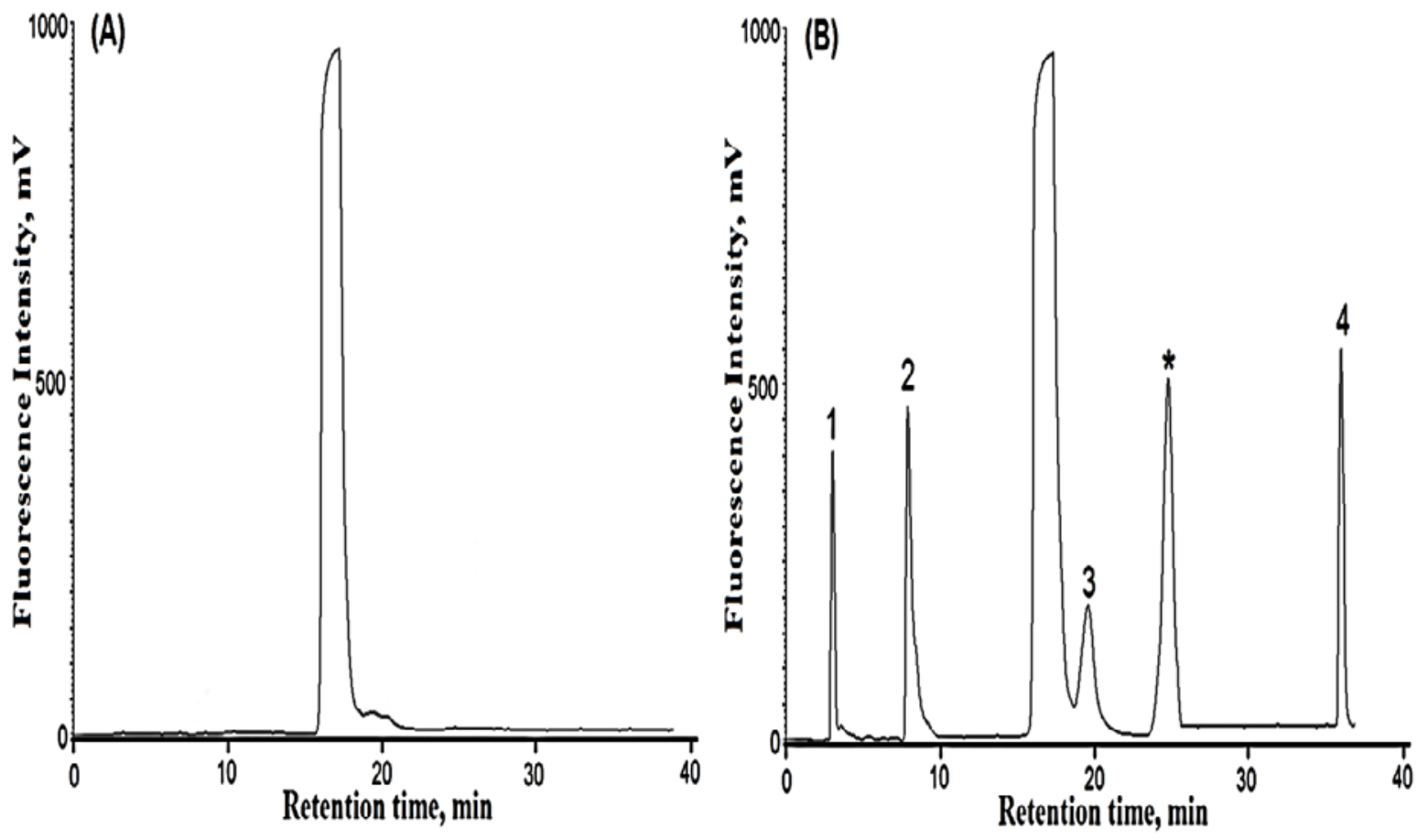

Figure 2 

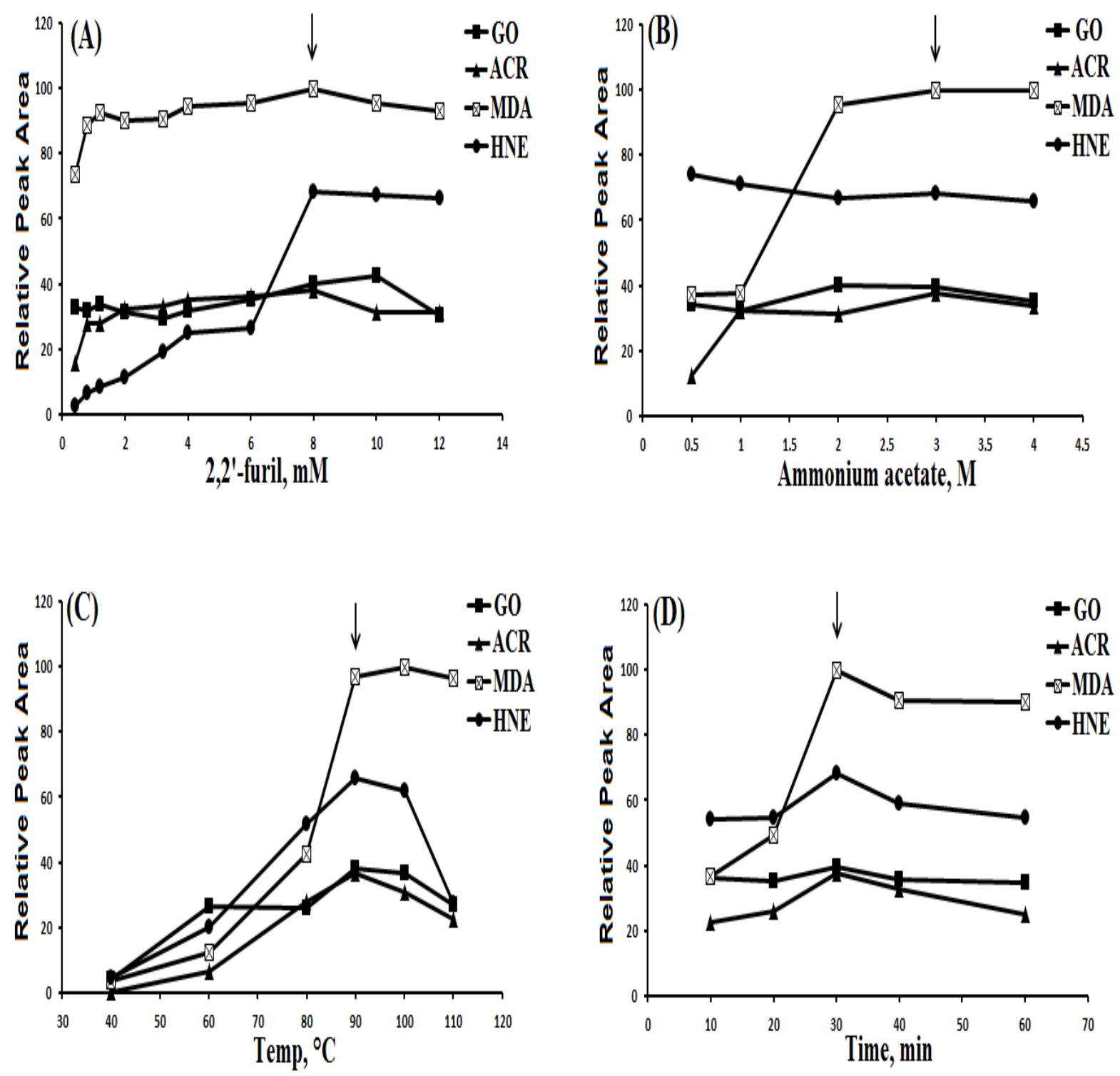

Figure 3 

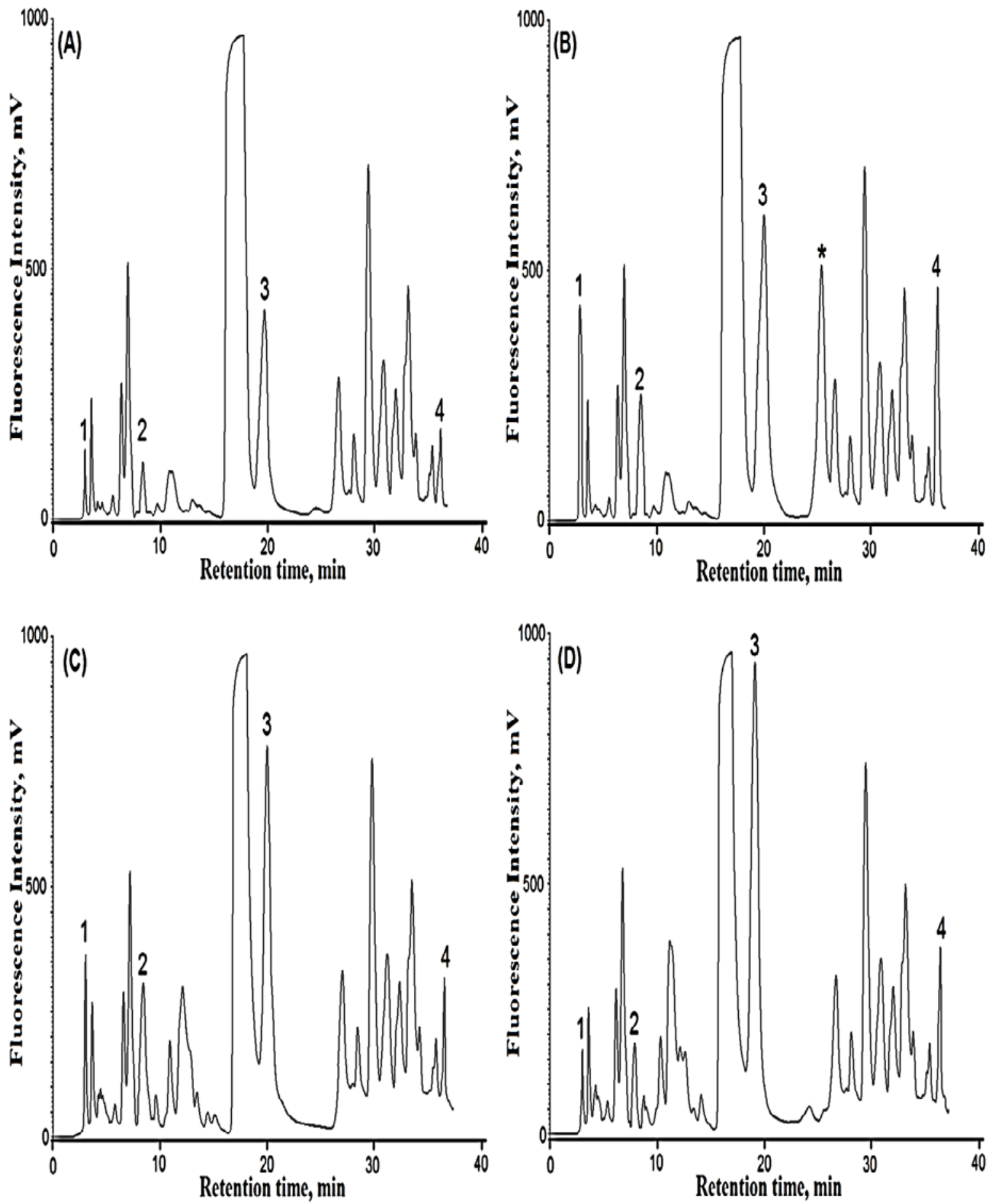

Figure 4 